\title{
The effect of empathy to bystander's role towards bullying at school through moral disengagement as a mediator
}

\author{
Yayah Durrotul Gholiyaha, H. Fuad Nashoria ${ }^{\mathrm{a}}$, Raden Rachmy Diana ${ }^{\mathrm{b}, *}$ \\ ${ }^{a}$ Department of Psychology, Faculty of Psychology and Socio-Cultural Sciences, Universitas Islam Indonesia, \\ Yogyakarta 55584, Indonesia \\ ${ }^{b}$ Department of Psychology, Faculty of Social Sciences and Humanities, Universitas Islam Negeri Sunan Kalijaga, \\ Yogyakarta 55281, Indonesia
}

Article history:

Received: 11 May 2021 / Received in revised form: 18 June 2021 / Accepted: 21 June 2021

\begin{abstract}
This study aims to illustrate the effect of empathy on the role of the bystander towards bullying at school through moral disengagement as the mediator. Moral disengagement affects bystanders' role. In this case, an outsider or ignorant bystander indicates higher moral disengagement than a defender or defensive bystander. The subject were 245 high school students in the age of 15-17 years. The respondents acted as bystanders adapted from the Participant Role Questionnaire (PRQ) scale. The researcher adopted the Basic Empathy Scale dan Moral Disengagement Scale as the measuring instrument. The data analysis employed a simple mediation analysis technique with bootstrapping method. The results indicated that first, there was a positive and significant effect of empathy on the role of defender bystander mediated by moral disengagement. Second, there was a negative and significant effect of empathy on reinforcer bystander's role towards bullying at schools as mediated by moral disengagement. Third, the study also indicated that there was no effect of empathy to the bystander's roles as an assistant, outsider, and aggressive defender through moral disengagement as a mediator. One of implications for future interventions in schools, for instance, bystander training emphasizing an effective way to act towards bullying at school.
\end{abstract}

Keywords: empathy; moral disengagement; bystander; bullying; teenagers

\section{Introduction}

Bullying in schools in Indonesian tends to increase each year. KPAI (Komisi Perlindungan Anak Indonesia) or Indonesian Child Protection Commission in 2020 revealed 1,828 bullying cases between January 2011 to August 2020, both as bullies and victims. Figure 1 shows the details on bullying cases in Indonesia.

The data from KPAI (2020) illustrated that children's cases between 2011 and 2019 were about 65,292 and mainly occurred in greater Jakarta (18,442 cases). The data implied that schools are less safe to study because bullying causes daily dysfunctions (on school assignments, friendship, and parents' involvement), stress, despair, and helplessness (Ybarra, Espelage, \& Mitchell., 2014). It is essential to reduce or minimize bullying in schools.

Bullying mainly occurs among teenagers. Volk, Farrell, Franklin, Mularczyk, and Provenzano (2016) asserted that $30-$ $40 \%$ of teenagers get involved in bullying with various roles. Volk et al. (2016) also indicated that bullying among teenagers occurs in senior high school, specifically marked by the

* Corresponding author.

Email: raden.diana@uin-suka.ac.id

https://doi.org/10.21924/chss.1.1.2021.11 transition from junior to senior high schools. The learning habits in senior high school are very different from junior high school. The habits grow with independence and loose supervision from elders (e.g., parents and teachers) outside the classrooms. Less supervision contributes a higher chance of bullying to occur with more negligible risks or impacts.

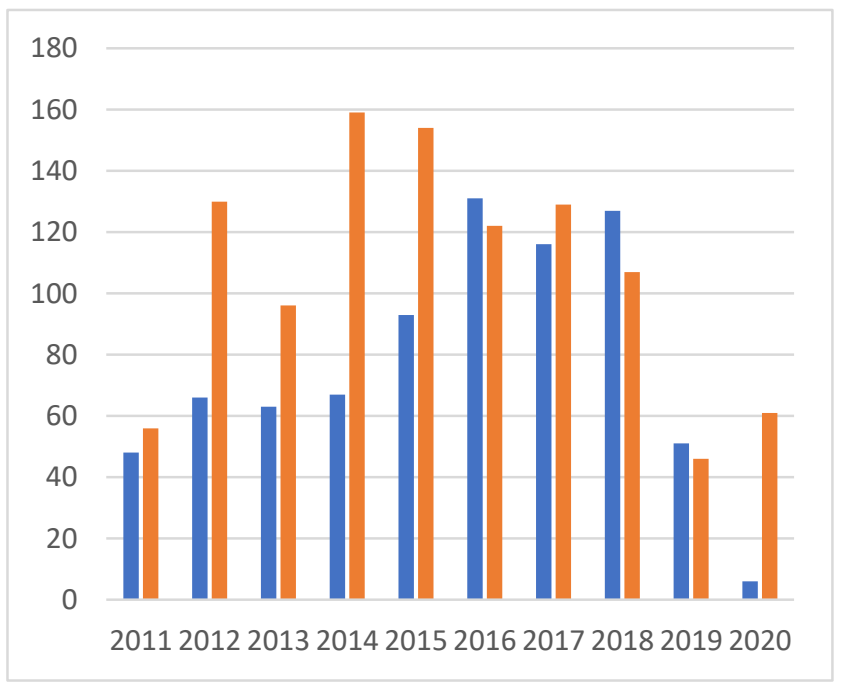

Fig. 1. Bullying cases in Indonesian school 
Bullying is unexpectedly aggressive behavior carried out by an individual or group of individuals that involve a power imbalance and tends to occur repeatedly (Gladden, Kantor, Hamburger \& Lumpkin 2014). Bullying is between bullies and the victim; moreover, it comprises witnesses or commonly addressed as a bystander (Padgett \& Notar, 2013). Padgett and Notar (2013) also mentioned when bullying occurs, a bystander has an essential role in preventing impact or damage from bullying, or vice versa. The role of a bystander can influence the bullying situation, either by preventing the event from occurring or by supporting the bully.

Raboteg-Šarić and Bartaković (2019) asserted that there are five roles of a bystander. They are the assistants (following or helping the bully), reinforcers (giving positive influence on the victim), defenders (helping or supporting the victim), outsiders (avoiding the event or doing nothing), and aggressive defenders (supporting the victim, both by verbal and physical aggressions and by making revenge to the bully). Additionally, Salmivalli, Lagerspetz, Bjorkqvist, Osterman, and Kaukiainen (1996) explaiedn that there are four roles of bystander: (a) assistant who assists or helps the bully, (b) reinforcer who provides a positive reinforcement to the bully, (c) defender who helps or takes a side on the victim, and (d) outsider who avoids or stays away from the bullying situation. In this study, the bystander's role covers five aspects: assistant, reinforcer, defender, outsider, and aggressive defender.

Various factors can influence the bystander's role, two of which are empathy and moral disengagement (Raboteg-Šarić \& Bartaković, 2019). On empathy, Zoll and Enz (2012) mentioned that it is the capacity and tendency of an observer to understand what other (target) thinks and feels of a particular condition. Detert, Trevino, and Sweitzer (2008) described empathy as a psychological condition that describes the extent to which individuals pay attention and concern for the needs of others. Zoll and Enz (2012) also signifed that empathy includes several aspects. First, the cognitive aspect is an ability to understand other people emotions from natural social interaction processes to have a clear picture of other people's perspectives. Second, the affective aspect is closely related to the process in which the observer's emotions appear consciously or unconsciously due to the target's internal state (e.g. emotions, thoughts, and attitudes). According to Bošnjaković and Radionov (2018), a person's empathy is influenced by neurochemistry (genetics), contextual (positive relation between observer and people around him/her, the degree of mutual affinity and similarity), and personality and psychopathology (damage in a particular part of the brain).

Menolascino (2016) argued that empathy influences the bystander's role. Raboteg-Šarić and Bartaković (2019) asserted that empathy, especially in its affective aspect, consistently correlates positively with pro-social attitude and negatively relates to aggressive and antisocial attitudes. Thus, a bystander who has high empathy tends to act as a defender. On the other hand, a bystander with low empathy tends to be an assistant, reinforcer, and outsider. Gini, Albiero, Benelli, and Altoe (2008) mentioned several aspects of empathy. The first is the cognitive component, which includes perspective taking, for instance, understanding other's emotion. The second is the affective component, which covers empathic attention, for example sympathizing with other people emotions. Cognitive understanding of others' feelings can be used against other individuals; in contrast, knowing what others feel is more likely to trigger behavior that will decrease their negative influence (Poyhonen, Juvonen \& Salmivalli 2010). A study by Nickerson, Aloe, Livingston, and Feeley (2014) indicated that empathy influences bystanders' role in bullying. Another study by Pöyhönen et al. (2010) also illustrated that empathy affects bystanders' role in bullying in which individuals with high affective empathy likely stand for bullying victims. Meanwhile, those with high cognitive empathy tend to act as an outsider or remain absent.

Aside from empathy, bystanders' role is also influenced by moral disengagement. It is a process in which individuals rationalize their involvement in an amoral attitude (Bandura, 1999). Bandura also illustrated eight psychological mechanisms on moral disengagement to justify one's unethical attitude. The mechanisms are moral justification, euphemistic language, good comparison, displacement of responsibility, diffusion of responsibility, distorting consequences, attribution of blame, and dehumanization. First, moral justification is moral release operating in cognitive reconstruction in the attitude itself. An individual commonly does not involve in dangerous behavior that may harm himself/herself until he/she justifies the morality of his/her behavior. In this justifying process, harmful behavior is personally created and socially accepted by displaying it as a socially or morally appropriate purpose. Therefore, people can act based on moral obligations and retain their opinions to justify their role as moral agents while they harm others.

Second, euphemistic labeling is labeling an immoral act with soft expressions. Language shapes mindset, which becomes the basis of an act, and it can be displayed differently, according to its label. Euphemism is widely used to label any dangerous acts to be honored and accepted and reduce personal responsibility upon the impact of the acts. Third, the advantageous comparison is another way to make harmful acts look appropriate. The way action is perceived contributed by the things compared to it. By using the contrastive principle, despicable acts can be justified. Fourth, the displacement of responsibility operates by blurring or minimizing the agent's role in a detriment made. Responsibility shifting makes one to see his/her act as an order from the authorities; thus, he/she has no personal obligation on the result. The individual can avoid self-blame reaction because he/she is not the actual agent of the act.

Fifth, the diffusion of responsibility is when a personal option is obscured by spreading responsibility upon harmful behavior. Individuals can behave more violently under group responsibility than personal responsibility. Sixth, disregard or distortion of consequences is an additional way to weaken moral control operated by ignoring or reversing the effects of one's acts. When individuals engage in harmful activities for personal gain or social pressure, they will avoid the harm they cause or minimize it. Seventh, dehumanization operates on the recipient of harmful acts. The power of self-moral censorship depends on how the perpetrator views an individual being persecuted. Correlative interpersonal experiences during formative years in which individuals experience collective happiness and hardship create a foundation for empathic 
response to others' suffering.

Eighth, the attribution of blame is an act of blaming others. Blaming other's conditions is considered as the way of escape from one's responsibility. In this process, individuals perceive themselves as victims who are driven by harmful acts of forced provocation. Therefore, punishing behavior is seen as a justifiable defensive reaction to opposing provocations. Selfliberation can also be achieved by seeing a person's dangerous behavior imposed by coercive circumstances - not personal decisions as correcting one's mistakes or circumstances. Selfharm can be forgiven, and an individual can even justify his/her acts in the process (Bandura, 1999).

Experts indicate that there is a negative effect of moral disengagement on the bystander's roles. Raboteg-Šarić and Bartaković (2019) stated that moral disengagement plays an essential role in bystander's role in a bullying event in addition to empathy. In their study, Raboteg-Šarić and Bartaković (2019) proved that moral disengagement has influenced bystanders' role towards bullying at school. Also, Thornberg and Jungert (2013) illustrated the effect of moral disengagement on bystanders' role towards a bullying situation. A study by Obermann (2011) showed that moral disengagement affects bystanders' role. In this case, an outsider or ignorant bystander indicates higher moral disengagement than a defender or defensive bystander. Raboteg-Šarić and Bartaković (2019) specifically mentioned that moral disengagement mechanisms deactivate a moral control and allow an individual to justify his/her aggressive behavior without experiencing any negative consequences upon his/her self-image. Hence, individuals who behave as the bystanders with high moral disengagement tend to commit violence or immoral acts with the role of assistant, reinforcer, and outsider. On the contrary, bystanders with low moral disengagement tend to behave positively by acting as a defender who helps the victim.

This study situated moral disengagement as a variable affecting the bystander's role and a mediating variable between empathy and the bystander's role. Moore (2015) claimed that moral disengagement is a variable that can act as a mediator. When moral disengagement is a process, it is studied as a mediator. Meanwhile, when moral disengagement is a trait, it is studied as a moderator. Moore (2015) also indicated that several studies explored moral disengagement as an intermediate effect predictor at the individual level, resulted from cognitive and behavioral moral problems. Bok (1998) further emphasized that empathy and the capacity to maintain other's feelings are the basis of morality. There is no morality without empathy (Detert et al., 2008). Therefore, empathy is an essential factor in morality that affects moral disengagement's occurrence. Detert et al. (2008) mentioned that individuals with high empathy are more likely to live others' feelings and pay attention to others' needs. As a result, highly empathetic individuals will not detach themselves from morally disengage processes, like, making moral justification of their acts that will harm or dehumanize others. Detert et al. also mentioned that empathy harms moral disengagement. Those who have higher empathy for others are less likely to get morally detached.

The study aimed to determine the effect of empathy on bystanders' role towards bullying situations in high schools with moral disengagement as the mediator. The first hypothesis is that there is a significant effect of empathy on the role of defender bystander mediated by moral disengagement. The second hypothesis is that there is a significant effect of empathy on the role of assistant bystanders as mediated by moral disengagement. The third hypothesis is that there is a significant effect of empathy on the role of outsider bystanders mediated by moral disengagement. The fourth hypothesis is that there is a significant effect of empathy on the role of aggressive defender bystander mediated by moral disengagement. The fifth hypothesis is that there is a significant effect of empathy on the role of reinforcer bystander as mediated by moral disengagement. The hypotheses are illustrated on a model in figure 2 .

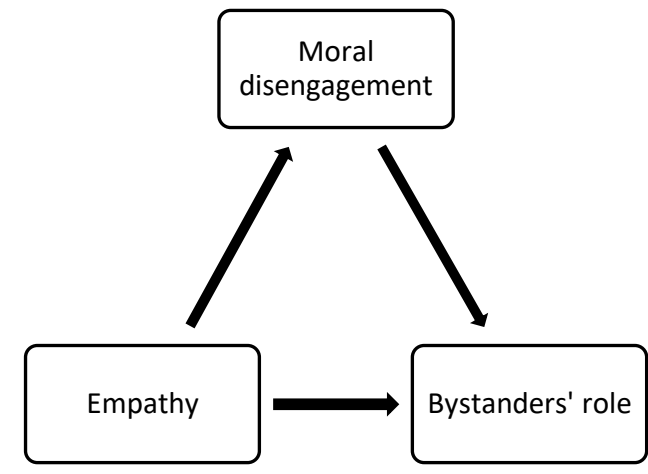

Fig. 2. The effect of empathy on the role of the bystander in bullying at school through moral disengagement as a mediator

\section{Methodology}

\subsection{Participant}

The participants were 245 senior high school students aged 15-17 and witnessed bullying at schools.

Table 1. Research participants $(\mathrm{N}=245)$

\begin{tabular}{cccc}
\hline Age & \multicolumn{2}{c}{ Sex } & Total \\
& Female & Male & \\
\hline 15 & 37 & 10 & 47 \\
16 & 87 & 43 & 130 \\
17 & 42 & 26 & 68 \\
Total & 166 & 79 & 245 \\
\hline
\end{tabular}

The data were taken in Jakarta as in a study held by KPAI (Komisi Perlindungan Anak Indonesia/Indonesian Child Protection Commission). In 2020, the highest rate of children cases $(18,442$ of 65,292 cases/28\%) occurred in Jakarta. In addition, the participants were also those who acted as bystanders, assessed by the adapted Participant Role Questionnaire (PRQ) scale. Participants filled out the Google form, and the criteria have been listed on the informed consent of Google form.

\subsection{Measurement}

The measuring scale used in the study was adapted from Participant Role Questionnaire (PRQ), Basic Empathy Scale (BES), dan Moral Disengagement scales. Researchers used back to back translate with English language experts and took 
a sample of respondents to read each item.

Participant Role Questionnaire (PRQ) scale is developed by Raboteg-Šrić and Bartaković (2019). The scale is an instrument used to describe various bystander behaviors in bullying situations at school. It consisted of 37 items with five factors of bystander roles, namely, assistant, reinforcer, defender, outsider, and aggressive defender. There were three options, namely $1=$ never, $2=$ sometimes, and $3=$ always.

After the researchers conducted a validity test and achieved valid items, they worked on a reliability test using SPSS 26. Cronbach's Alpha scores for each aspect on PRQ scale were 0.878 (defender); 0.682 (assistant); 0.661 (outsider); 0.666 (aggressive defender); and 0.651 (reinforcer). Thus, 34 items in the PRQ scale were reliable or consistent, as described in table 2 .

Table 2. Reliability test on PRQ scale

\begin{tabular}{lcc}
\hline Bystander Role & Item & Alpha Coefficient \\
\hline Defender & 14 & 0.878 \\
Assistant & 6 & 0.682 \\
Outsider & 4 & 0.661 \\
Aggressive Defender & 4 & 0.666 \\
Reinforcer & 5 & 0.651 \\
\hline
\end{tabular}

Basic Empathy Scale (BES) is developed by Mikac, Busko, Ivanovic, and Cikes (2017). It measures individual empathic report, which covers both cognitive and affective components. It consists of two aspects; cognitive empathy and affective empathy with 22 items ( 11 items on cognitive empathy and 11 items on affective empathy). It uses a Likert scale with four options (4=strongly agree, $3=$ agree, $2=$ disagree, $1=$ strongly disagree). In this study, the validity test indicated that the items were valid; moreover, the researchers worked on a reliability test with SPSS 26. Cronbach's Alpha score for the basic empathy scale resulted in 0.777 showing that 11 items in the scale were reliable or consistent (table 3 ).

Table 3. Alpha Cronbach of basic empathy scale

\begin{tabular}{cc}
\hline No & Cronbach's Alpha if Item Deleted \\
\hline ITEM 1 & .751 \\
ITEM 2 & .794 \\
ITEM 3 & .761 \\
ITEM 4 & .759 \\
ITEM 5 & .765 \\
ITEM 6 & .766 \\
ITEM 7 & .773 \\
ITEM 8 & .743 \\
ITEM 9 & .742 \\
ITEM 10 & .734 \\
ITEM 11 & .764 \\
\hline
\end{tabular}

Moral Disengagement Scale (MDS) is developed by Bandura et al. (1996) to measure vulnerability level on moral disengagement from various harmful behaviors in multiple contexts and interpersonal relationships. The scale has been developed from eight moral disengagement mechanisms: moral justification, euphemistic language, advantageous comparison, displacement of responsibility, diffusion of responsibility, distorting consequences, attribution of blame, and dehumanization. Cronbach's Alpha score for the Moral Disengagement scale resulted in 0.894. It indicated that 26 items in the scale were reliable or consistent (table 4).

Table 4. Alpha cronbach the moral disengagement scale

\begin{tabular}{lc}
\hline No & Cronbach's Alpha if Item Deleted \\
\hline ITEM 1 & .892 \\
ITEM 2 & .890 \\
ITEM 3 & .889 \\
ITEM 4 & .890 \\
ITEM 5 & .888 \\
ITEM 6 & .890 \\
ITEM 7 & .892 \\
ITEM 8 & .894 \\
ITEM 9 & .892 \\
ITEM 10 & .888 \\
ITEM 11 & .890 \\
ITEM 12 & .888 \\
ITEM 13 & .894 \\
ITEM 14 & .891 \\
ITEM 15 & .888 \\
ITEM 16 & .892 \\
ITEM 17 & .888 \\
ITEM 18 & .887 \\
ITEM 19 & .889 \\
ITEM 20 & .891 \\
ITEM 21 & .894 \\
ITEM 22 & .889 \\
ITEM 23 & .887 \\
ITEM 24 & .889 \\
ITEM 25 & .893 \\
ITEM 26 & \\
\hline
\end{tabular}

\subsection{Procedure}

The study was conducted in five steps. First, the researchers prepared a proposal and the second step was to prepare the measuring instruments. The researchers arranged them by adapting several measuring instruments. Third, the researchers tested the measuring instruments to examine their reliability and validity. The measuring instruments have received ethical clearance from Ethics Committee, Faculty of Psychology and Socio-Cultural Sciences, Universitas Islam Indonesia, as registered in No. 358/Dek/70/DURT/XI/2020. The next step was data collection in which the researchers conducted online recruitment using Google form. Participants declared ready to participate voluntarily. The fourth step was data processing. The researchers started to measure respondents' scores, as well as counted and recorded the data tabulation and finally made tables from the data obtained. Next, the researchers worked on data analysis with statistical methods to test the researcher's hypotheses. The final step was to draft a research report.

\subsection{Data analysis}

The data analysis used a simple mediation analysis technique with the bootstrapping method. It was performed with SPSS program version 26, and simple mediation analysis was carried out using PROCESS v3.5 macro for SPSS (Hayes, 2018). Simple mediation analysis could observe direct, indirect, and total effects. 


\section{Results and discussion}

\subsection{Results}

Before testing the hypothesis with a simple mediation model, an assumption test was carried out using a KolmogorovSmirnov normality test. Based on the results of the normality test, the data distribution was found not normal. The bootstrapping method can carry out testing structural equation modeling with abnormal data distribution (Cheung \& Lau, 2008).

The method involves multiple data resampling with a replacement to produce an empirical estimation on the entire statistical sampling distribution; therefore, it can be used when the distribution assumption is violated, i.e., when the data distribution is not normal (Cheung \& Lau, 2008). The analysis was carried out according to the five dimensions in the bystander's role variable. The results of empathy regression analysis on moral disengagement included $\mathrm{b}=-1.35, \mathrm{SE}=0.13$, $\mathrm{t}=10.00$, and $\mathrm{p}<0.01$. Effective contribution of this model $\left(\mathrm{R}^{\wedge} 2\right)$ is $0.29 ; \mathrm{F}(1.243)=100.1919$, and $\mathrm{p}<0.01$. The results of the empathy regression analysis on moral disengagement are shown in figure 3.

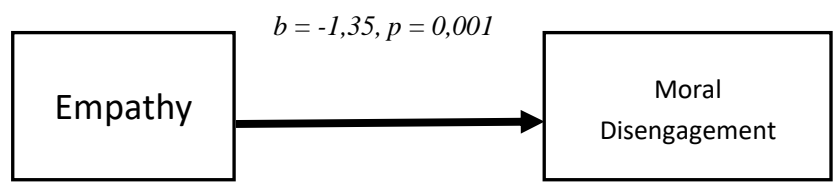

Fig. 3. The effect of empathy on the role of the bystander towards bullying at school

Firstly, the results of regression analysis of moral disengagement on bystander's role as defender were $b=-0.08$, $\mathrm{SE}=0.04, \mathrm{t}=-1.98$, and $\mathrm{p}<0.05$. Effective contributions of the model $\left(\mathrm{R}^{\wedge} 2\right)$ are $0.17 ; \mathrm{F}(2.242)=25.9635$, and $\mathrm{p}<0.01$. Next, the results of regression analysis of empathy on bystander's role as defender were $b=0.51, \mathrm{SE}=0.10, \mathrm{t}=4.75$, and $p<0.01$. The indirect effects of empathy on the role of the bystander as defender through moral disengagement were $b=$ 0.51 , BootLLCI (lower level for CI) $=0.29$, and BootULCI (upper level for $\mathrm{CI}$ ) $=0.72$. The mediation test showed a $95 \%$ bias-corrected confidence interval $(\mathrm{BCa} \mathrm{CI})$ in the range of 0.29 to 0.72 . Zero was not included in the $95 \%$ confidence interval range; therefore, there was a significant indirect effect of empathy on bystanders' role as a defender through moral disengagement. The analysis model results for the first dimension, namely bystanders' role as a defender, are shown in figure 4 .

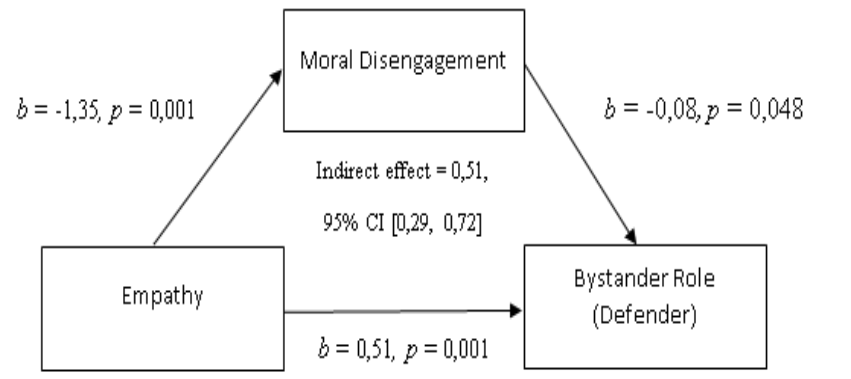

Fig. 4. The effect of empathy on the role of the bystander (defender) towards bullying at school through moral disengagement as a mediator
Secondly, the results of regression analysis of moral disengagement on bystander's role as reinforcer were $b=0.06$, $\mathrm{SE}=0.12, \mathrm{t}=4.36$, and $\mathrm{p}<0.01$. The effective contributions of the $\left(\mathrm{R}^{\wedge} 2\right)$ model were $0.07 ; \mathrm{F}(2.242)=9.5095$, and $\mathrm{p}<0.01$. Next, the results of regression analysis of empathy on bystander's role as reinforcer were $\mathrm{b}=0.08, \mathrm{SE}=0.03, \mathrm{t}=2.40$, and $\mathrm{p}<0.05$. The indirect effect of empathy on bystander's role as reinforcer through moral disengagement was $b=-0.08$, BootLLCI (lower level for CI) $=-0.13$, and BootULCI (upper level for $\mathrm{CI})=-0.03$. The mediation test showed a $95 \%$ biascorrected confidence interval $(\mathrm{BCa} \mathrm{CI})$ in the range of -0.13 to -0.03 . Zero was not included in the $95 \%$ confidence interval range, and there was a significant indirect effect of empathy on the role of the bystander as reinforcer through moral disengagement. The analysis model results for the second dimension, namely bystander's role as a reinforcer, are presented in figure 5 .

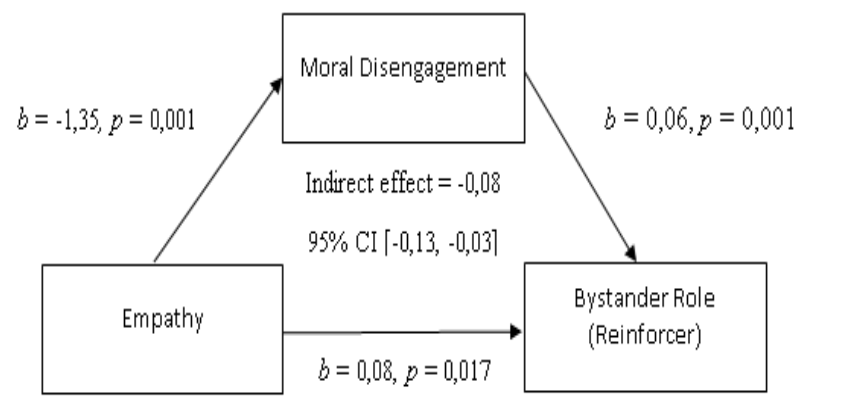

Fig. 5. The effect of empathy on the role of the bystander (reinforcer) towards bullying at school through moral disengagement as a mediator

Thirdly, the results of regression analysis of moral disengagement on bystander's role as assistant were $b=0.02$, $\mathrm{SE}=0.01, \mathrm{t}=2.64$, and $\mathrm{p}<0.01$. The effective contributions of the model $\left(\mathrm{R}^{\wedge} 2\right)$ were $0.04 ; \mathrm{F}(2.242)=5.1362$, and $\mathrm{p}<0.01$. Next, the results of regression analysis of empathy on bystander's role as assistant were $\mathrm{b}=-0.01, \mathrm{SE}=0.02, \mathrm{t}=0.10$, and $p>0.05$. The indirect effects of empathy on bystander's role as assistant through moral disengagement were $b=-0.03$, BootLLCI (lower level for CI) $=-0.06$, and BootULCI (upper level for $\mathrm{CI})=0.00$. The mediation test showed a $95 \%$ biascorrected confidence interval $(\mathrm{BCa} \mathrm{CI})$ in the range of -0.13 to -0.03 . For zero it was not included in the $95 \%$ confidence interval range and there was no significant indirect effect of empathy on the role of the bystander as assistant through moral disengagement. The analysis model results for the third dimension, namely bystander's role as an assistant, are presented in figure 6 .

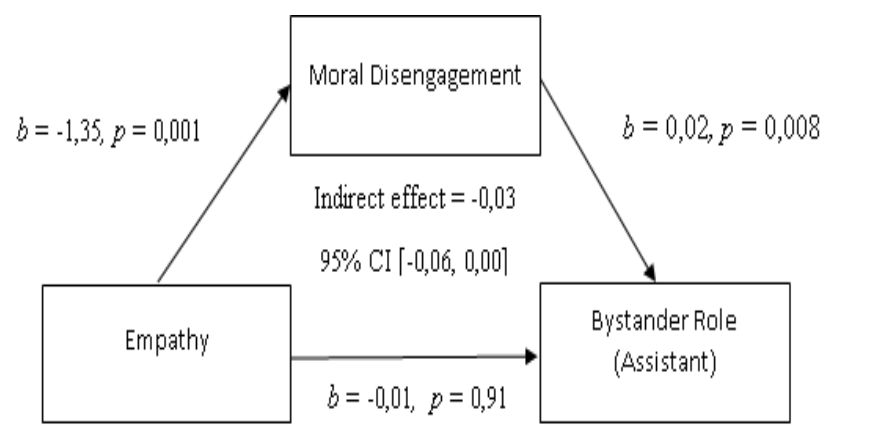

Fig. 6. The effect of empathy on the role of the bystander (assistant) towards bullying at school through moral disengagement as a mediator 
Next, the results of regression analysis of moral disengagement on bystander's role as outsider were $b=0.01$, $\mathrm{SE}=0.01, \mathrm{t}=0.45$, and $\mathrm{p}>0.05$. The results of regression analysis of empathy on bystander's role as outsider were $\mathrm{b}=$ $0.10, \mathrm{SE}=0.03, \mathrm{t}=-3.28$, and $\mathrm{p}<0.01$. The indirect effects of empathy on bystander's role as outsider through moral disengagement were $\mathrm{b}=-0.01$, BootLLCI (lower level for CI) $=-0.04$, and BootULCI (upper level for $\mathrm{CI}$ ) $=0.03$. The mediation test showed a $95 \%$ bias-corrected confidence interval $(\mathrm{BCa} \mathrm{CI})$ in the range of -0.04 to 0.03 . For zero, it was not included in the $95 \%$ confidence interval range as there was no significant indirect effect of empathy on the role of the bystander as an outsider through moral disengagement. The analysis model results for the fourth dimension, namely bystander's role as an outsider, are depicted in figure 7 .

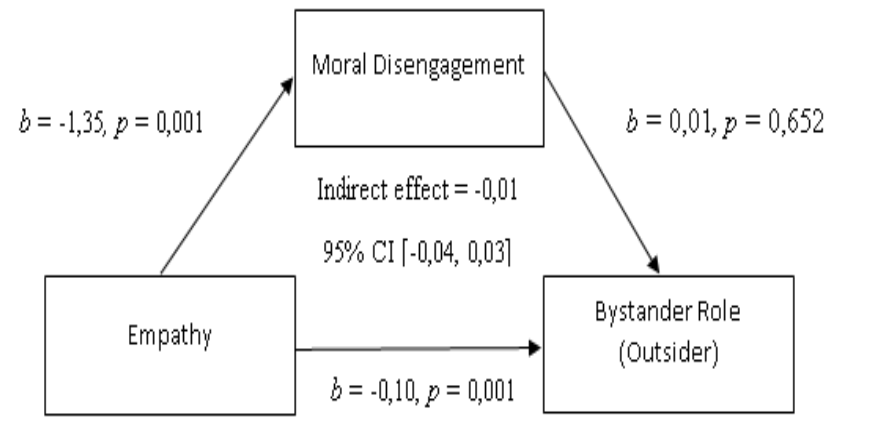

Fig. 7. The effect of empathy on the role of the bystander (outsider) towards bullying at school through moral disengagement as a mediator

Finally, the results of regression analysis of moral disengagement on bystander's role as aggressive defender were $\mathrm{b}=0.02, \mathrm{SE}=0.02, \mathrm{t}=1.45$, and $\mathrm{p}>0.05$. The results of regression analysis of empathy on bystander's role as aggressive defender were $\mathrm{b}=0.13, \mathrm{SE}=0.04, \mathrm{t}=3.45$, and $\mathrm{p}<0.01$. The indirect effects of empathy on bystander's role as aggressive defender through moral disengagement were $b=$ 0.03, BootLLCI (lower level for CI) $=-0.07$, and BootULCI (upper level for $\mathrm{CI})=0.01$. The mediation test showed a $95 \%$ bias-corrected confidence interval $(\mathrm{BCa} \mathrm{CI})$ in the range of 0.07 to 0.01 . For zero it was not included in the $95 \%$ confidence interval range as there was no significant indirect effect of empathy on the role of the bystander as an aggressive defender through moral disengagement. The analysis model results for the fifth dimension, namely the bystander's role as aggressive defender, are presented in figure 8 .

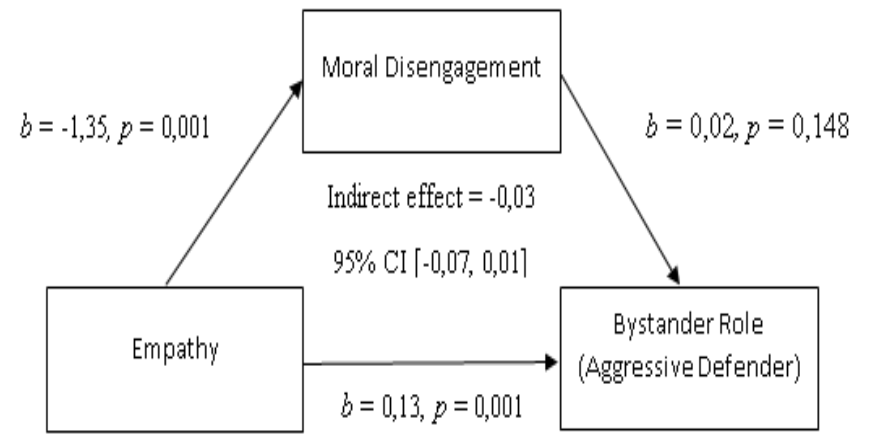

Fig. 8. The effect of empathy on the role of the bystander (aggressive defender) towards bullying at school through moral disengagement as a mediator

\subsection{Discussion}

The results indicated that empathy mediated by moral disengagement positively influenced bystanders' role as a defender. Additionally, empathy mediated by moral disengagement negatively influenced the bystander's role as a reinforcer. Meanwhile, there was no effect of empathy, mediated by moral disengagement, on bystander's role either as assistant, outsider, or as aggressive defender.

There was a moral disengagement's mediating effect that positively influenced empathy on the bystander's role as a defender. Detert et al. (2008) mentioned that individuals with high empathy are more likely to understand others' feelings and pay attention to others' needs. As a result, highly empathetic individuals will not detach themselves from morally disengage processes, like, making moral justification of their acts that will harm or dehumanize others. Therefore, a bystander who has high empathy tends to have a low moral disengagement. It then affects the bystander's tendency to act as a defender who helps or supports bullying victims.

Accordingly, Raboteg-Šarić and Bartaković (2019) stated that empathy consistently has a positive correlation with the bystander's role as a defender; moreover, moral disengagement becomes a mediator that influences empathy bystanders' role as a defender. It indicates that individuals with high empathy tend to have a low moral disengagement and will further influence bystander's tendency to act as a defender.

Wang, Yang, and Zao (2017) also illustrated that empathy is negatively associated with moral disengagement. The higher one's empathy, the lower his/her moral disengagement. Furthermore, Wang et al. emphasized that moral disengagement plays a vital role as a mediator, which influences empathy on aggression and antisocial behavior. Individuals with a high level of empathy will reduce aggression and antisocial behavior through a decreased moral disengagement and vice versa. Hence, there is a moral disengagement's mediating effect, which influences empathy on the bystander's role as a defender. In this case, the defender's role includes pro-social behavior, for instance, helping the bullying victims and providing a support to them.

Further mediation analysis indicated a mediating effect of moral disengagement, as shown in the negative effect of empathy on bystander's role as a reinforcer. A bystander who has high empathy and, in the process, is in low moral disengagement tends to drop the role of reinforcer by supporting bullies. The results are also in line with a study by Wang et al. (2017). It illustrated that moral disengagement plays an essential role as a mediator regarding the influence of empathy on aggression (in this sense, the role of the bystander as reinforcer). Individuals with a high level of empathy may reduce aggression (in this sense, the role of the bystander as reinforcer). It is indicated by a decrease in moral disengagement and vice versa. Even though the empathic response has an essential correlation to pro-social behavior, it cannot be considered a sufficient condition; other variables may be necessary for supporting or limiting students' pro-social behavior (Gini et al., 2008). Therefore, empathy is influenced by other variables that influence bystanders in taking a role in bullying situations. The one discussed in this study is the moral disengagement variable. 
Raboteg-Šarić and Bartaković (2019) pointed out that going against strong and loyally supported bullies require empathy to the victim and obeys a moral standard that highlights it correctly. Empathy consistently has a negative influence on moral disengagement. In their study, Raboteg-Šarić and Bartaković indicated that moral disengagement positively influences bystander's role as a reinforcer.

Next, the results indicated no moral disengagement mediating effect, which influenced empathy on the bystander's role as assistant, outsider, and aggressive defender. A study by Obermann (2011) illustrated that bystanders as outsiders have a high moral disengagement. Therefore, the absence of moral disengagement's mediating effect on empathy with bystander's role as outsider causes low empathy and other variables that may significantly support or limit pro-social behavior (Gini et al., 2008). A bystander who acts as an outsider may have a high moral disengagement. Therefore, empathy for the bystander's role as an outsider is not mediated by moral disengagement.

Next, there is no moral disengagement's mediating effect on empathy on bystander's role as an aggressive defender. Raboteg-Šarić and Bartaković (2019) mentioned that aggressive defenders play a role in which bystanders take less constructive ways of dealing with bullying situations to support victims. It includes verbal aggression, physical aggression, and retaliatory behavior aimed at the bully. Even though an aggressive defender has a supportive role, there are still aggressive acts against the bullying perpetrator. Wang et al. (2017) indicated that empathy is considered an essential human capacity in reducing aggressive behavior.

Moreover, moral disengagement is a variable that becomes a risk factor in aggression. Hence, the absence of moral disengagement's mediating effect on empathy with the bystander's role as an aggressive defender is possible because it includes the acts of aggression. It occurs when there is a process of moral disengagement in defending the victim. Raboteg-Šarić and Bartaković (2019) highlighted that the higher the moral disengagement, the bigger the tendency of bystanders to act as aggressive defenders.

Next, moral disengagement does not mediate the influence of empathy on the bystander's role as an assistant or an ally to bully. It goes in contrary to the study by Wang et al. (2017). The study demonstrated that moral disengagement has a mediating effect on empathy with aggression in which the assistant's role includes aggression in it. According to Hyde, Shaw, and Moilanen (2010), moral disengagement mediates empathy and antisocial behavior. In this case, antisocial behavior is included in the bystander's role as assistant. Additionally, the research respondents in both studies were boys. It allows different results with this study where most of the respondents were the girls.

\subsection{Research limitations}

The study has several limitations. First, the scales used were the adaptations; hence, the number of items was disproportionate, and the number of respondents was inadequate compared to the number of items. Furthermore, Gini et al. (2008) explained that empathy is a variable that cannot be treated sufficiently to determine pro-social behavior on a bystander. Many other essential variables can influence the bystander in deciding his/her role in bullying situations. For example, the social self-efficacy variable mediates the influence between empathy and bystander's role as defender and outsider. Yudhani, Nashori, and Uyun (2020) proposed the level of religiosity as a variable. The higher the level of religiosity teenagers have, the lower the moral disengagement. Therefore, the religiosity variable needs to be further investigated. Further study can examine the effect of moral disengagement, which influences bystanders' role, significantly as a defender and aggressive defender, to reduce bullying in schools.

\section{Conclusion}

The results indicated a significant influence of empathy mediated by moral disengagement on the role of the bystander as a defender. The second hypothesis was accepted, as there was a significant influence of empathy mediated by moral disengagement on the role of the bystander as a reinforcer. The third hypothesis was rejected since there was no significant effect of empathy mediated by moral disengagement on the bystander's role as assistant. The fourth hypothesis was rejected because there was no significant effect of empathy mediated by moral disengagement on the bystander's role as an outsider. The fifth hypothesis was also rejected since there was no significant influence of empathy mediated by moral disengagement on the bystander's role as an aggressive defender. Further research needs to expand the scope of other contributing factors to see variables that can influence the role of the bystander in bullying situations at school. The study discovered that variants' proportion on bystander's role by empathy and moral disengagement was only a few percent. The researchers believe that there is still a relatively large percentage of other variables influencing the bystander's role. In addition, further research needs to consider other mediating variables to see the influence of empathy on the bystander's role. The research can also use a more significant number of samples to describe the population better. The findings of this study may have some important implications for future interventions in schools, for instance, bystander training, which emphasizes an effective way to act on bullying at school.

\section{Acknowledgements}

The authors would like to express thanks to the leader of Professional Psychology Master Program, Faculty of Psychology and Socio-Cultural Sciences, Universitas Islam Indonesia, Yogyakarta, Indonesia.

\section{References}

Bandura, A. (1999). Personality and Social Psychology Review Moral Disengagement in the Perpetration of Inhumanities. Personality and Social Psychology Review, 3(3), 179-192.

Bandura, A., Barbaranelli, C., \& Caprara, G. V. (1996). Bandura, Albert, and Claudio Barbaranelli, Gian Vittorio Caprara, and Concetta Pastorelli (1996), Mechms of Moral Disengagt in the Exercise of Moral Agency, JPSP, 71(2), 364-374.pdf. Journal of Personality and Social Psychology, 71(2), 364-374. 
Bošnjaković, J., \& Radionov, T. (2018). Empathy: Concepts, theories and neuroscientific basis. Alcoholism and Psychiatry Research, 54(2), 123-150.

Cheung, G. W., \& Lau, R. S. (2008). Testing mediation and suppression effects of latent variables: Bootstrapping with structural equation models Organizational Research Methods, 11(2), 296-325.

Detert, J. R., Treviño, L. K., \& Sweitzer, V. L. (2008). Moral Disengagement in Ethical Decision Making: A Study of Antecedents and Outcomes. Journal of Applied Psychology, 93(2), 374-391.

Gini, G., Albiero, P., Benelli, B., \& Altoè, G. (2008). Determinants of adolescents' active defending and passive bystanding behavior in bullying. Journal of Adolescence, 31(1), 93-105.

Gladden, R. M., Vivolo-Kantor, A. M., Hamburger, M. E., \& Lumpkin, C. D. (2014). Bullying surveillance among youths. Centers for Disease Control and Prevention Atlanta, Georgia, 4-101.

Haddock, A. D., \& Jimerson, S. R. (2017). An Examination of Differences in Moral Disengagement and Empathy Among Bullying Participant Groups. Journal of Relationships Research, 8, 1-15.

Hayes, A. F. (2018). Introduction to Mediation; Moderation; and Conditional Process Analysis (T. D. Little (ed.); second). New York London: The Guilford Press.

Hyde, L. W., Shaw, D. S., \& Moilanen, K. L. (2010). Developmental precursors of Moral Disengagement and the role of Moral Disengagement in the development of antisocial behavior. Journal of Abnormal Child Psychology, 38(2), 197-209.

KPAI. (2020). Update Data Infografis KPAI - Per 31-09-2020. 31 September. Menolascino, N. (2016). Empathy, perceived popularity and social anxiety: Predicting bystander intervention among middle school students. The International Journal of Emotional Education, 5(2), 67-79. https://thekeep.eiu.edu/theses/2507.

Moore, C. (2015). Moral disengagement. Current Opinion in Psychology, 6, 199-204.

Nickerson, A. B., Aloe, A. M., Livingston, J. A., \& Feeley, T. H. (2014). Measurement of the bystander intervention model for bullying and sexual harassment. Journal of Adolescence, 37(4), 391-400.

Obermann, M. L. (2011). Moral disengagement among bystanders to school bullying. Journal of School Violence, 10(3), 239-257.
Padgett, M. S., \& Notar, C. E. (2013). Bystanders are the Key to Stopping Bullying. Universal Journal of Educational Research, 1(2), 33-41.

Pöyhönen, V., Juvonen, J., \& Salmivalli, C. (2010). What does it take to stand up for the victim of bullying? the interplay between personal and social factors. Merrill-Palmer Quarterly, 56(2), 143-163.

Raboteg-Šarić, Z., \& Bartaković, S. (2019). Empathy and moral disengagement as predictors of bystander roles in school bullying. Central European Journal of Paediatrics, 15(2), 161-176.

Salmivalli, C., Lagerspetz, K., Björkqvist, K., Österman, K., \& Kaukiainen, A. (1996). Bullying as a group process: Participant roles and their relations to social status within the group. Aggressive Behavior, 22(1), 1-15.

Sorayah. (2018). Uji Validitas Konstruk Beck Depression Inventory-II (BDIII). Jurnal Pengukuran Psikologi Dan Pendidikan Indonesia (JP3I), $4(1)$.

Thornberg, R., \& Jungert, T. (2013). Bystander behavior in bullying situations: Basic moral sensitivity, moral disengagement and defender selfefficacy. Journal of Adolescence, 36(3), 475-483.

Volk, A. A., Farrel, A. H., Franklin, P., Mularczyk, K. P., \& Provenzano, D. A. (2016). Evolutionary Perspectives on Child Development and Education. Evolutionary Perspectives on Child Development and Education, 1-356.

Wang, X., Lei, L., Yang, J., Gao, L., \& Zhao, F. (2017). Moral Disengagement as Mediator and Moderator of the Relation Between Empathy and Aggression Among Chinese Male Juvenile Delinquents. Child Psychiatry and Human Development, 48(2), 316-326.

Ybarra, M. L., Espelage, D. L., \& Mitchell, K. J. (2014). Differentiating youth who are bullied from other victims of peer-aggression: The importance of differential power and repetition. Journal of Adolescent Health, 55(2), 293-300.

Yudhani, E., Nashori, F., \& Uyun, M. (2020). The Effect Of Family Functioning on Moral Disengagement In Adolescents Mediated By Religiosity. Psikis : Jurnal Psikologi Islami, 6(2), 178-191.

Zoll, C., \& Enz, S. (2012). A Questionnaire to assess affective and cognitive empathy in children. 9 . 